\title{
ESTAÇÕES FERROVIÁRIAS EM BAURU (1917-1939): O ECLETISMO E O ART DECO, MARCAS DA REPÚBLICA VELHA E DA ERA DE VARGAS NO INTERIOR DO ESTADO DE SÃO PAULO
}

\author{
Railway Stations of Bauru (1917-1939): The Eclecticism and Art Deco, Marks from the Old \\ Republic and from the Vargas Era, in the Interior of São Paulo State
}

Estaciones de Ferrocarriles em Bauru (1917-1939): El Eclecticismo y el Art Deco, Huellas de La República Vieja y de La Era Vargas en el Interior Del Estado de São Paulo

Fabio Paride Pallotta ${ }^{1}$

A "gare” de Bauru. As palavras do professor Rocha Lima sobre a Estação da Noroeste:

\begin{abstract}
Já comentamos o que representa para esta zona a promessa que o professor Dr. Rocha Lima, diretor do Instituto Biológico, formulou quando aqui esteve há poucos dias: uma secção daquelle importante departamento seria installada em Baurú para atender toda a região. Há uma referência porém, na entrevista que nos concedeu que merece comentário especial. Homem que tem viajado largamente pela Europa e por outros continentes s. s. disse que só na Itália e Alemanha paizes que têm renascido para o seu antigo explendor, viu estações ferroviárias do porte da que esta sem conclusão em Baurú. Deve desvanecer-nos, o confronto de tão illustre brasileiro lembremo-nos do antigo director da Noroeste, o engenheiro Alfredo de Castilho, sem a sua iniciativa da qual a grandiosa "Gare" continuaria a ser, não se sabe até quando aquilo que fora muitos e muitos annos, desde o tempo da extincta companhia: - um simples e simpático projeto ${ }^{2}$.
\end{abstract}

\section{RESUMO}

O presente trabalho tem como objetivo apresentar os estilos arquitetônicos das Estações de Ferro de Bauru, entre 1917 e 1939, como marcos simbólicos do poderio das oligarquias cafeeiras da República Velha (1889-1930) e da Era Vargas (1930-1945) com seu estilo Eclético e Art Deco, respectivamente.

Palavras-chave: Estações Ferroviárias, República Velha, Era Vargas.

\section{ABSTRACT}

This paper aims to present the architectural style of the Stations Iron from Bauru between 1917 and 1939 as landmarks, symbols of the power of coffee oligarchies of the Old Republic (1889-1930) and the Vargas Era (1930-1945) with his Eclectic style and Art Deco respectively.

Keywords: Railway Stations, the Old Republic, Vargas Era.

\footnotetext{
${ }^{1}$ Mestre em História e Sociedade pela Faculdade de Ciência e Letras - Campus Unesp Assis - São Paulo; Docente do Curso de História da Universidade Sagrado Coração - Patrimônio Cultural; Pesquisador do Grupo de Pesquisa Gênero, Sexualidade e Sociedades (Cnpq/Usc); Membro do Codepac-Bauru (Conselho de Defesa do Patrimônio Cultural de Bauru). E-mail: historiaferramenta@terra.com.br.

${ }^{2}$ Correio da Noroeste, ano VII, no 2123, 01/06/1938, p.1.
} 


\title{
RESUMEN
}

Este trabajo tiene como objetivo presentar el estilo arquitectónico de las Estaciones de Ferrocarril de Bauru entre 1917 y 1939 como puntos de referencia, como símbolos del poder de las oligarquías cafetaleras de la República Vieja (1889-1930) y la Era Vargas (1930-1945) con su estilo Ecléctico y Art Deco, respectivamente.

Palabras clave: Estaciones de Ferrocarril, Republica Vieja, Era de Vargas.

\section{Introdução}

A cidade de Bauru surgiu a partir da expansão das lavouras de café, pelo Oeste Paulista, mas só desenvolveu-se com a chegada das ferrovias paulistas: a Companhia Estrada de Ferro Sorocabana-EFS, em 1905, a Companhia de Estradas de Ferro Noroeste do BrasilEFNOB, também em 1905 e a Companhia de Estradas de Ferro Paulista-Cia. Paulista, em 1910.

Apesar da importância das estradas de ferro na modernização da cidade de Bauru, elas não possuíam estações de embarque e desembarque adequadas para servir a população e para transportar as mercadorias a contento, como relatou o Correio de Bauru de 1925:

As primeiras impressões de quem visita Bauru

\begin{abstract}
Não são das melhores, as impressões que da cidade, no seu exterior formulam á primeira vista, os nossos forasteiros. Isto quando eles desembarcam em qualquer das tentações férreas locaes. A Sorocabana possue acanhado barracão de tijolos. Sua plataforma estreitíssima, suja, offerece sério perigo aos que nella aguardam os trens em dias de movimento intenso, que não são raros. Este movimento redunda em largos proventos que a estrada offerece, na parte que respeita a venda de passagens em Baurú. A Noroeste nos serve em um segundo barracão extenso, e este de madeira com defficientes acomodações deante do movimen to diário de viajantes que ali facilmente se observa. Estação provisória em vias de substituição como adeante falaremos (Correio de Bauru, anno X, nº 1184, 10/12/1925, p.1).
\end{abstract}

$\mathrm{Na}$ cidade de Bauru, no início do século $\mathrm{XX}$, as estações eram pequenas e de arquitetura ferroviária tradicional, distante dos anseios das elites que pretendiam que o principal ponto de chegada à cidade fosse semelhante às imagens idealizadas de um "cartão de visitas":

(...) sem grandes variações e com raras exceções, os modelos europeus. As estações de passagem e os terminais ferroviários apresentaram as mesmas características construtivas e plásticas das européias, isto é, as estruturas metálicas (quando existiam) se justapunham aos maciços de alvenaria, sem integração plástica (GUEDES, 2003). 
Mas não eram apenas as estações que causavam mal estar entre os habitantes da cidade: a própria existência e administração das ferrovias estavam sob cerradas críticas, pois a EFNOB, que nascia em Bauru, contava com a sua administração lotada no Rio de Janeiro, à época, Capital Federal da República. Para tentar resolver esta situação, foi escolhido como administrador da EFNOB o engenheiro Arlindo Gomes Ribeiro da Luz (NEVES, 1958: 140), ou Arlindo Luz como ficou conhecido na cidade de Bauru.

Ele trouxe para Bauru todo o pessoal da administração da EFNOB, que devido ao fato de terem se deslocado do Rio de Janeiro para o interior do Estado de São Paulo começaram a ser chamados de "Os Cariocas", trazendo novas sociabilidades às quais a sociedade bauruense não estava acostumada. Além disso, construiu e inaugurou um novo complexo de oficinas que pela sua dimensão e complexidade só foi alcançado pela indústria automobilística no ABC paulista quarenta anos depois:

(...) Inauguradas no início dos anos 1920, junto a um setor de expansão urbana, afastado do núcleo central, as oficinas e rotunda (utilizada para manobrar as locomotivas) demonstram claramente pela escala e porte a transferência da sede da N.O.B. para a cidade de Bauru, efetivada em 1918, juntamente com a encampação da ferrovia pela União (...). As instalações das oficinas, se comparadas a dimensão da cidade, na época com 15 mil habitantes expressavam que o conjunto pertencia não a escala local, e sim a uma estrada de ferro de mais de $1200 \mathrm{~km}$, que interligava estados e países (...). Para atender as imensas necessidades da ferrovia foi construída uma verdadeira cidade industrial, que centralizava suas principais atividades (...) era clara a divisão de trabalho bem como o processo de montagem, que ao nosso ver, só passa a ser igualado nesta proporção, em nosso país, com a vinda das indústrias automobilísticas para o ABC paulista quarenta anos depois (...) (GHIRARDELLO, 2001: 04).

\section{Novas estações e estilos: exercício de poder e mando}

O engenheiro Arlindo Luz, além das monumentais Oficinas, começou a realizar diversas melhorias na EFNOB com a compra de trilhos de melhor qualidade da Bélgica: "Melhoramentos na Noroeste - Chegaram os novos trilhos belgas que serão colocados por obra e engenho do snr. Arlindo Luz que traçou um programa de reconstrução da Estrada" (O Bauru, anno XV, nº 723, 28/07/1921, p.1).

O diretor da EFNOB, em prestação de contas de sua administração para o Ministro da Viação, J. Pires do Rio relatou as condições em que encontrou a Estrada de Ferro Noroeste do Brasil em Relatório referente ao ano de 1921. Declarava o engenheiro: 
Exmo. Sr. Ministro:

Ao assumir V. Exa. a pasta da Viação e Obras Publicas a Noroeste achava-se ainda absolutamente desapparelhada para attender a seus objectivos. Linha sem dormentes de Baurú até Porto sperança; trilhos fraquíssimos e em extremo gastos no trecho da antiga Baurú-Itapura; estações quase todas provisórias, de madeira já apodrecida, sem áreas para abrigar as mercadorias desembarcadas ou a embarcar; material de tracção e de transporte insufficente e em mau estado de conservação; falta de officinas e de abrigos para o material rodante; ausência de ponte sobre o Rio Paraná, determinando o estrangulamento do trafego entre São Paulo e Matto Grosso; pontes provisórias sobre innumeras travessias, em muitas das quaes os trilhos são lançados sobre simples fogueiras de dormentes (...) (...) falta de disciplina em grande parte do pessoal cujos quadros se achavam em phase de reorganização e adaptação consequientes à incorporação da linha Baurú-Itapura, encampada em 1918, à ItapuraCorumba, já de propriedade do Governo e por ella administrada; tudo influía para os serviços de trafego, apezar dos esforços da administração se fizessem com graves irregularidades, sem pontualidade e sem segurança, ameaçando de ruína a grande fortuna particular empenhada na exploração industrial de uma das mais férteis regiões da nossa pátria (ESTRADA DE FERRO NOROESTE DO BRASIL. Relatório referente ao exercício de 1921. Bauru, p.3).

Além de tentar colocar ordem na questão administrativa, Arlindo Luz recebeu a incumbência de construir uma nova estação ferroviária "à altura" da cidade e da EFNOB, estrada de ferro estratégica, para integração com o Mato Grosso, diferente das demais estradas de ferro paulistas que tinham como principal atividade estarem a serviço do café.

O projeto foi elaborado de acordo com o estilo arquitetônico eclético que fora adotado nas remodelações das cidades, ocorridas no Brasil em fins do século XIX e início do século XX, com o advento da República. O Brasil havia mudado de regime político e com ele foi adotado outro estilo arquitetônico, o eclético que, se não oficial, rompeu com os antigos ditames construtivos.

O estilo arquitetônico eclético, apesar de usar muitos elementos decorativos, era um estilo construtivo aceito pelas pessoas de então: portas e janelas mais bem enquadradas e vedadas; o uso de banheiros com pias, bidês e vasos sanitários, condição possível pela criação de rede de água e esgoto nas cidades, que passavam a adotar tanto um urbanismo incipiente, quanto novas formas de higiene (REIS FILHO, 2002). De acordo com Reis Filho, na arquitetura ferroviária o eclético se mostrava pelas peças de ferro fundido que compunham a gare de embarque com grande trabalho artístico de decoração e os elementos já mencionados:

(...) Os agentes sociais dessas transformações, membros das camadas sociais urbanas em ascensão, atuariam sob influência do positivismo e do ecletismo arquitetônico. Essas camadas iriam construir e utilizar uma arquitetura mais atualizada e tecnicamente elaborada, sem o auxílio do trabalho escravo (REIS FILHO, 2002: 145). 
A população ficou entusiasmada com a possibilidade da construção da estação ferroviária da EFNOB que deveria ser grande e vistosa para "abrilhantar" as elites locais. O projeto da nova estação da EFNOB, bem como das plantas, foram aprovadas na seguinte ordem: 29 de junho de 1922, planta baixa; 19 de agosto, fachada principal e no dia 19 de setembro a fachada lateral. Estas datas foram encontradas nas respectivas plantas com assinatura de Arlindo Luz, diretor-engenheiro da Noroeste e Olavo F. de Oliveira, engenheiro responsável pela seção técnica da $\mathrm{V}^{\mathrm{a}}$ Divisão responsável pelas obras novas.

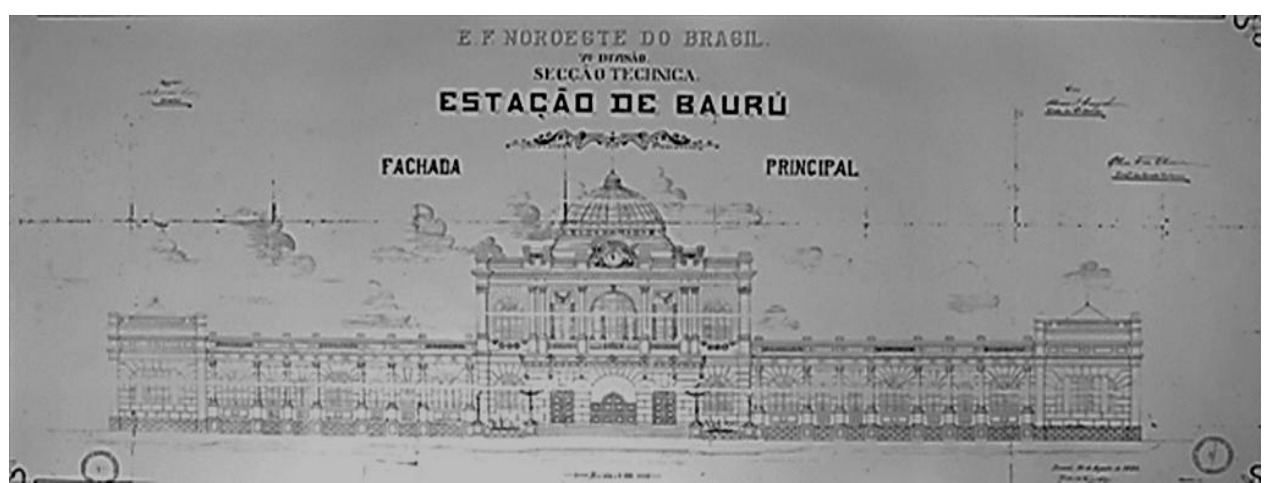

Fig. 1: Fachada principal da nova estação da Noroeste em Bauru. ESTRADA DE FERRO NOROESTE DO BRASIL Relatório da Diretoria referente ao exercício de 1921. Projeto da administração do diretor-engenheiro Arlindo Luz de 1922, nunca construída. Planta avulsa.

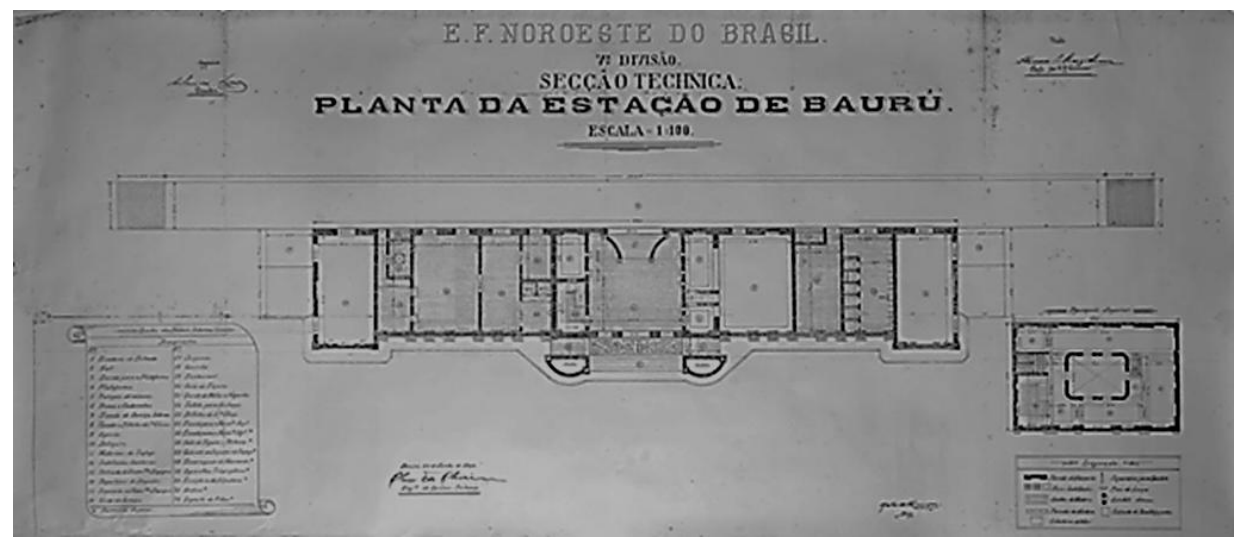

Fig. 2: Planta Baixa da nova estação da Noroeste em Bauru. ESTRADA DE FERRO NOROESTE DO BRASIL Relatório da Diretoria referente ao exercício de 1921. Projeto da administração do diretor-engenheiro Arlindo Luz de 1922, nunca construída. Planta avulsa. 


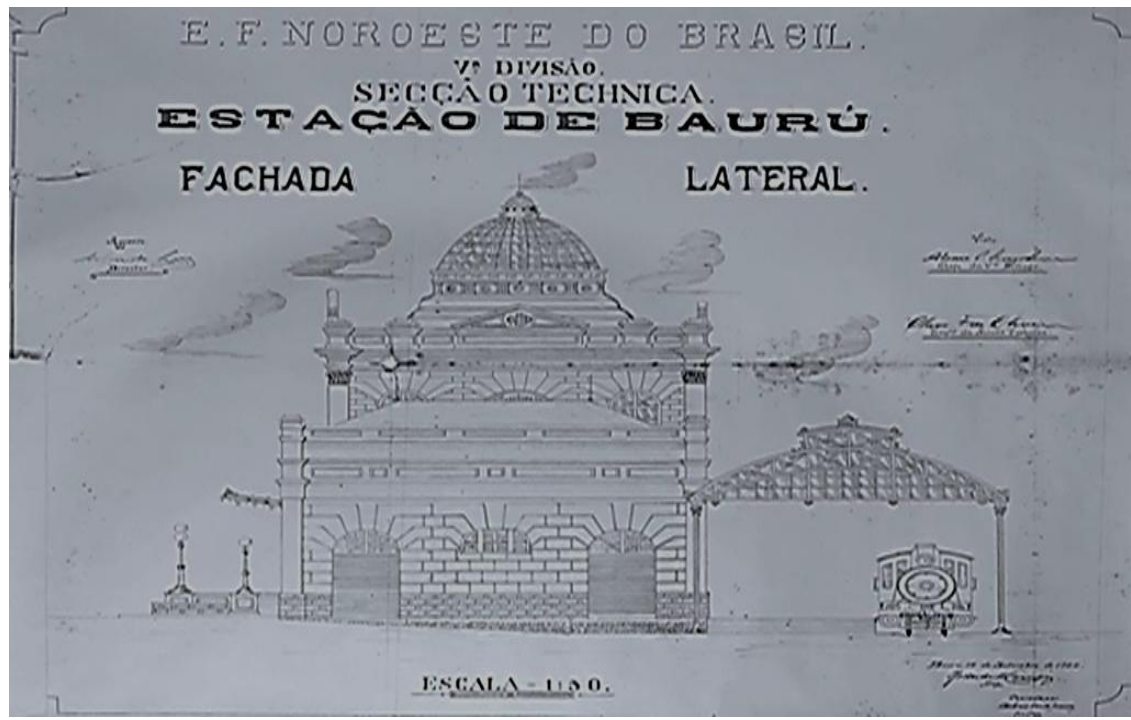

Fig. 3: Corte Lateral da nova estação da Noroeste em Bauru. ESTRADA DE FERRO NOROESTE DO BRASIL Relatório da Diretoria referente ao exercício de 1921. Projeto da administração do diretor-engenheiro Arlindo Luz de 1922, nunca construída. Planta avulsa.

O projeto da nova estação da EFNOB nunca saiu do papel. Provavelmente, devido ao momento político pelo qual o Brasil passava naquele instante, com o início das Revoltas Tenentistas, que indicavam a insatisfação das classes médias urbanas com a República Velha. Paralelamente, o Modernismo Brasileiro também indicava a insatisfação presente nas artes, literatura, pintura, escultura ainda que grande parte dos modernistas fosse das elites letradas dos cafeicultores de São Paulo.

Apesar do abandono do projeto de estação da Republica Velha, Bauru não perdia a esperança de que a cidade ganhasse sua nova estação ferroviária:

\begin{abstract}
Nova Estação
No dia 7 do corrente (novembro) o snr. Presidente da República assignou o decreto aprovando o projecto para a construção da Nova Estação da Estrada Noroeste nesta cidade, construcção esta que será iniciada brevemente. É um edifício magnífico e que muito vira embelezar a nossa cidade.

Agora que a Noroeste vae iniciar esta grande obra, esperamos que as Estradas Sorocabana e Paulista se resolvam também a construir as suas estações fazendo com que desappareçam os actuais barracões (O Bauru , anno XVI, $n^{\circ}$ 852, 09/11/1922, p. 2$)^{3}$.
\end{abstract}

Através da Revolução de 1930, assume o poder Getúlio Dornelles Vargas, com novas propostas para o Brasil. Dentro do espírito de racionalizar e melhorar a administração pública no país criou a Sociedade de Melhoramentos, responsável pela modernização e investimentos nas ferrovias do estado de São Paulo, em especial a EFNOB. Com essa nova

\footnotetext{
${ }^{3}$ Vale lembrar que a nova estação só foi construída muito mais tarde e o engenheiro diretor Arlindo Luz, como dito anteriormente, ficou decepcionado com a desatenção para com a sua administração. Outra frustração da administração Luz foi a não construção da ponte sobre o Rio Paraná, eleita como questão de honra de sua passagem pela Noroeste, anunciada e também não construída. Devido a essas manifestações de falta de prestígio político junto ao Ministério da Viação e Obras Públicas, Arlindo Luz requereu a sua exoneração.
} 
característica, foi dado início a construção da nova Estação Central, que não seria mais só da Estrada de Ferro Noroeste do Brasil, mas reuniria todas as ferrovias paulistas que possuíam linhas-tronco na cidade. Além da EFNOB, a Estação Central seria formada pela Companhia de Estradas de Ferro Sorocabana e pela Companhia de Estradas de Ferro Paulista. Ao centro estaria a EFNOB, no lado direito a Cia. Paulista e no lado esquerdo, a Estrada de Ferro Sorocabana.

O estilo adotado foi o Art Deco ${ }^{4}$, que deveria deixar claro que o Poder Público era exercido por novos arranjos políticos com Getúlio Vargas, no Executivo Federal. Sua atuação política se dava pela aproximação junto aos cidadãos em ocasiões especiais, marcando presença, ocupando espaços e mostrando sua autoridade, deixando claro a sua capacidade de atuar em várias instâncias da economia, da política, bem como exercer poder simbólico, que nesse caso, se mostrava pela construção da tão almejada Estação Central (REVEL, 1990: $104)^{5}$.

Em 1938, portanto já no período do Estado Novo, Getúlio Vargas fez uma visita à Bauru. Foi acompanhado do interventor de São Paulo, Adhemar de Barros, antigo político do Partido Republicano Paulista e, à época, membro dos quadros do Estado Novo Varguista. Na cidade, Vargas passou em revista à construção da Estação Central, fez contatos políticos e em especial deixou claro que, apesar do aspecto festivo, a ditadura do Estado Novo era uma realidade e tinha o apoio de uma grande parte do exército:

Baurú recebe amanhã (20 de julho) a visita do chefe da Nação.

Em companhia do sr. Getúlio Vargas e de sua esposa e filha vêm a sra. e o sr. Adhemar de Barros, interventor federal em São Paulo, o interventor fluminense comandante Amaral Peixoto, o General José Pinto, chefe da Casa Militar da Presidência e outras altas personalidades - A viagem será feita em aviões que voarão directamente do Rio até Baurú, iniciando-se aqui a excursão presidencial pelo nosso Estado (Correio da Noroeste, anno VIII, nº 2154, 19/07/1938, p.1).

\footnotetext{
${ }^{4}$ BRESLER, H. O Art Decoratif Moderno na França. In: $1^{\circ}$ Seminário Internacional Art Deco na América Latina. Rio de Janeiro: Prefeitura da Cidade do Rio de Janeiro. Em Art Deco (diminutivo de Art Decoratif, termo que passou a ser usado a partir de 1925, em comemoração à exposição de Art Decoratif em Paris) de caráter monumental. Reunia todas as ferrovias existentes na cidade, com uma justaposição espacial. Esse estilo arquitetônico nasceu na exposição Internacional de Artes decorativas e Industriais Modernas de 1925 em Paris (Exposition Internationale dês Arts Decoratifs et Industriels Modernes) como uma reação aos excessos cometidos pelo Art Nouveau. Sua proposta era purificar e liberar os edifícios da exuberância do Art Nouveau, passando a ter fachadas planas eliminando desenhos simbólicos, linhas contorcidas inspiradas na flora, jogos de curvas, tudo em nome da higiene, da economia e da modernização.

${ }^{5}$ REVEL, J. A invenção da sociedade. In: Coleção Memória e Sociedade. (...) o conhecimento do território é a produção do território (...) p. 104; (...) A viagem de Estado oferece assim um recurso que jamais será esquecido. A sua formula será afinada pouco a pouco, a montagem mais elaborada, as intenções mais complexas, mas é a mesma estratégia de constituição e de legitimação do poder soberano pelo território que irá a partir daí atravessar os séculos. (..) p. 106.
} 
O exército marcou presença na administração da EFNOB através do major Américo Marinho Lutz, militar do exército, escolhido para administrar a EFNOB por ter a confiança dos seus companheiros de farda e de Getúlio Vargas. Essa confiança ficou patente em discurso proferido pelo administrador castrense em comemoração ao seu primeiro ano de administração, quando foi agraciado com um banquete com centenas de talheres, mostra de seu prestígio político. A Política dos Banquetes era prática comum para demonstrar a concordância com a política desenvolvida pelo homenageado e mostrar seu prestígio entre seus pares:

\section{O DISCURSO DO MAJOR MARINHO LUTZ}

Agradecendo a homenagem prestada á sua pessoa o major Marinho Lutz, director da E. F. Noroeste pronunciou o seguinte discurso:

"Senhores. Aceitando e agradecendo esta homenagem, não o faço, entretanto, somente em meu nome, senão também, em nome da Noroeste, que tenho a honra de dirigir e de todos que nella mourejam diariamente no cumprimento do dever.

(...) No exercício desta funç̧ão que me confiou o Governo da República, não respondo somente pelos actos de simples administrador, sugeito, na concepção geral, á prestação de contas do ponto de vista monetário. Si, por um lado, estou na obrigação de dar conta do patrimônio que me foi entregue, por outro pesa-me sobre os ombros o dever de honrar os galões que me foram confiados pelo Exército Nacional. De uma como de outra, posso dar contas ao Governo e aos meus companheiros de farda aqui presentes com a consciência do dever cumprido. (...) [Folha do Povo, anno 5, nº 501, 24/04/1939, p.2 (grifos meus)].

Na nova Estação Central, o Art Deco deveria demonstrar, com sua monumentalidade e pureza de formas, a supremacia e dominação do Estado Varguista sobre o Estado de São Paulo, dominando os espaços territoriais, em especial aqueles mais recentemente ocupados, como a região Noroeste.

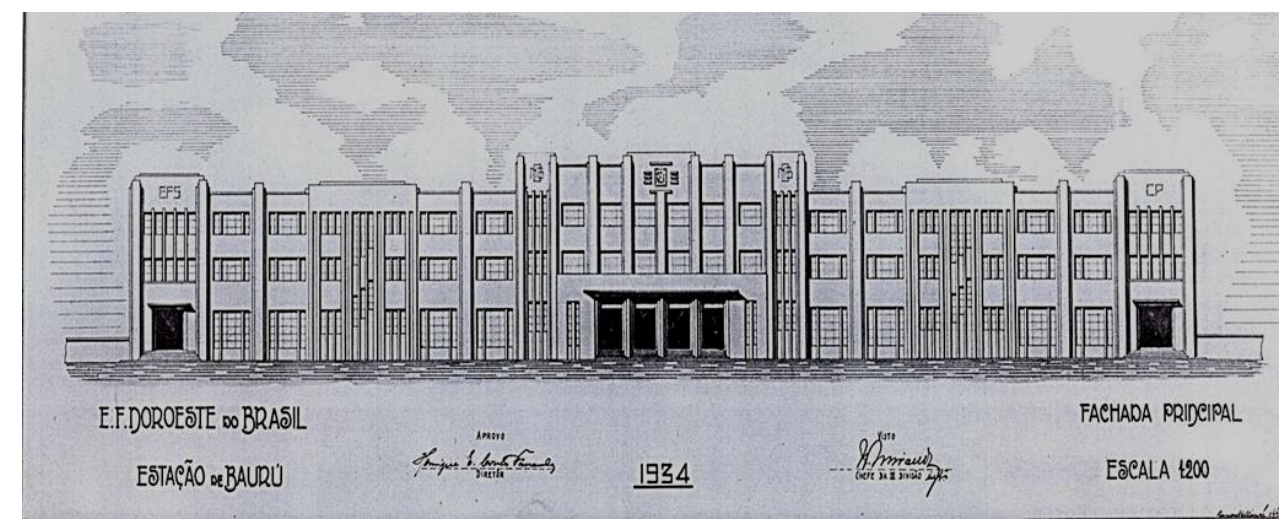

Fig. 4: Croqui da nova Estação Central de Bauru. ESTRADA DE FERRO NOROESTE DO BRASIL Relatório da Diretoria referente ao exercício de 1933. Recebeu as três ferrovias paulistas mais importantes, com evidente destaque para a $E F N O B$ que ficou ao centro da construção, dominando a entrada para o embarque de passageiros e o controle do tempo através do relógio. À direita, a administração da Cia. Paulista e a esquerda a

Estrada de Ferro Sorocabana. As três com uma gare de embarque e desembarque comum. 
Com 10.756m2 de área construída, incluindo a Gare (área de embarque e desembarque), seus arcos de sustentação do teto foram feitos de concreto armado, tecnologia já dominada pela engenharia nacional desde a década de 1920, mas nunca usada em obra ferroviária de tal envergadura. Esta técnica construtiva substituiu o uso de estruturas metálicas de preponderância estrangeira como o proposto no projeto eclético da EFNOB de 1922, do diretor engenheiro Arlindo Luz.

O Art Deco não foi a linguagem arquitetônica "oficial" do varguismo, mas da forma como foi usada na construção da Estação Central, este estilo arquitetônico “(...) assim será visto. Quando monumental representará o poder central: sólido e poderoso... Refletirá o novo e a mudança, mesmo que o novo signifique uma reciclagem do velho e a mudança se dê apenas nas camadas de superfície" (GHIRARDELLO, 2002: 08).

Eis que se materializou a Estação Central, "um gigantesco prédio, com grandioso visual... assumindo concretamente a expressão máxima de posse do lugar e do seu imaginário" (POSSAS, 2001: 150).

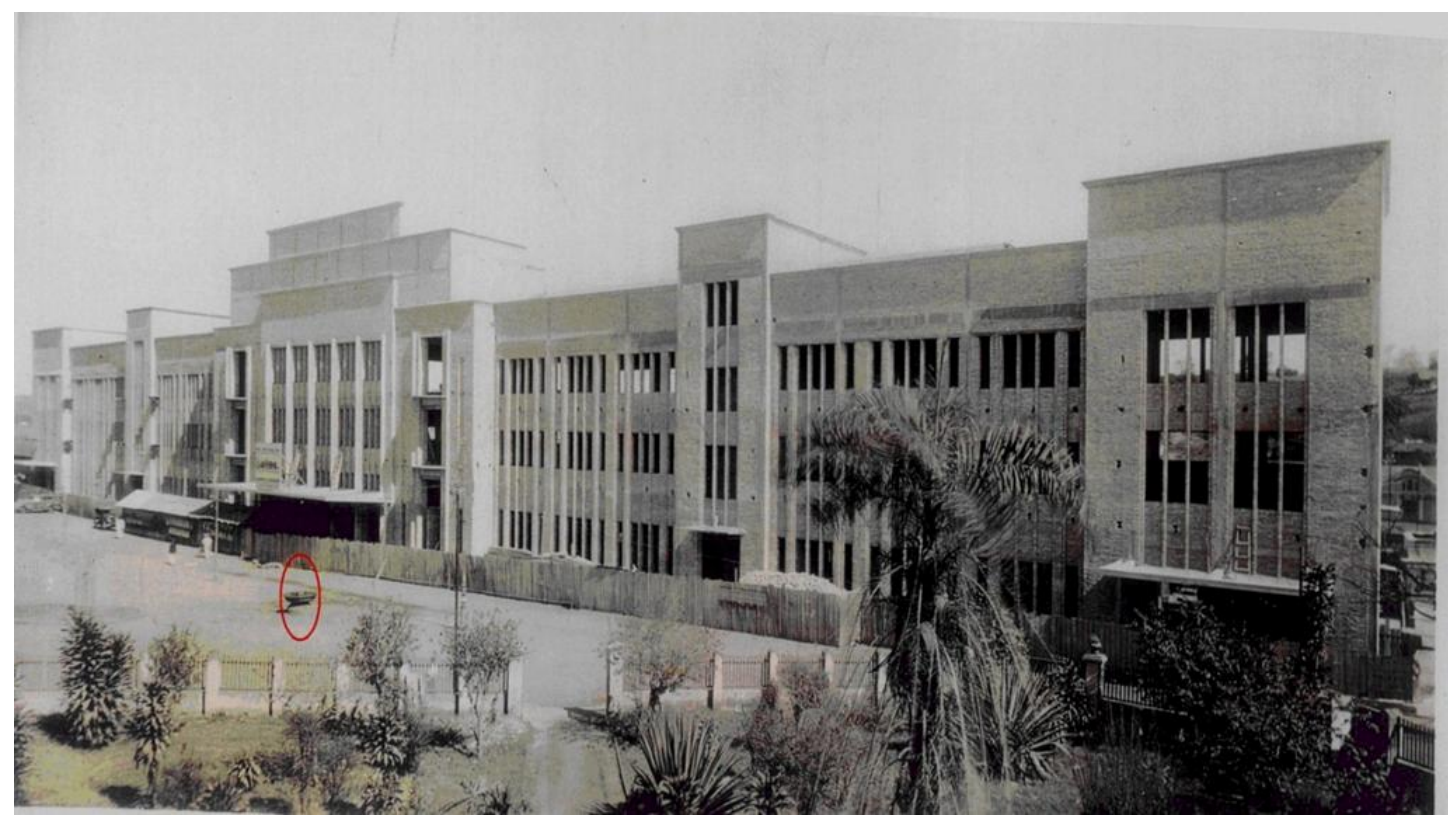

Fig. 5: Estação Central em Art Deco em construção. Bebedouro animal com um círculo vermelho. ESTRADA DE FERRO NOROESTE DO BRASIL Relatório da Diretoria referente ao exercício de 1935. À esquerda o bebedouro para cavalos (destacado pelo círculo vermelho).

Apesar da audácia do projeto e da execução da Estação Central, ficou na fotografia oficial da sua construção, uma marca sobre a realidade urbana de Bauru, à época: apesar dos 
avanços materiais e da modernização trazidas pelas ferrovias, a cidade ainda era umbilicalmente ligada à realidade rural e agrícola como ficou claro na presença de um bebedouro para cavalos à esquerda da fotografia.

\section{Considerações finais}

Em uma cidade agrícola e dependente do café como Bauru, a ferrovia representou um impulso modernizante que modificou a cidade, suas sociabilidades, suas representações. Dentro dessas mudanças, gozar de um serviço ferroviário de qualidade era fundamental.

As estações, peças chave nessa intrincada equação atormentavam a todos pela sua rusticidade e descompromisso com o funcional, com a prestação de um serviço de qualidade. A população e as elites da cidade ressentiam-se do seu aspecto acanhado, além de não cumprirem a contento com sua finalidade: transportar as pessoas com conforto e segurança e enviar mercadorias com presteza e eficiência.

Os projetos das estações ferroviárias de Bauru, para substituírem as estações existentes e precárias, foram desenvolvidos a partir dos moldes da República Velha (18891930) pelo engenheiro diretor Arlindo Luz, no estilo eclético, que a todos contentaria, mas não foi executado, provavelmente pela situação política institucional que o país vivia, mas deixou claro sua inspiração no sentido da modernização conservadora.

Sem execução da estação em estilo eclético, representando os ideais do Partido Republicano Paulista, Bauru entrou na era Vargas (1930-1945) com a execução da estação ferroviária, conhecida como Estação Central, em estilo Art Deco que deveria impressionar e deixar um recado claro de quais eram os novos caminhos a seguir, sendo abandonado o modelo anterior, mas não as alianças anteriores.

Os reclamos da imprensa a respeito das antigas estações cessaram a partir do início das obras da nova Estação Central. A construção em si ocupou pouco espaço na imprensa, embora fosse lembrada devido às formas arrojadas para a época: por ser monumental e por seu simbolismo. Deve-se lembrar de que aquela construção, fora de escala para cidade, impressionava as elites comerciais que esperavam a normalização do fluxo de mercadorias necessárias para continuar construindo o progresso material da cidade de Bauru. Seu processo construtivo e as soluções arquitetônicas de concreto armado da engenharia nacional fugiam do ferro fundido tradicional da arquitetura ferroviária do período eclético anterior.

A Estação Central de Bauru "resolveu" a questão das estações ferroviárias da cidade naquele momento, e demonstrou com sua audácia do projeto e nas soluções construtivas qual 
era a sua finalidade simbólica para a qual tinha sido erigida: a marca do poder da nova orientação política do país naquele momento.

\section{Referências bibliográficas}

BRESLER, H. O Art Decoratif Moderno na França. In: $1^{\circ}$ Seminário Internacional Art Deco na América Latina. Rio de Janeiro: Prefeitura da Cidade do Rio de Janeiro. 1997.

CORREIO DE BAURU, anno X, No 1184, 10/12/1925, P.1.

CORREIO DA NOROESTE, anno VII, nº 2123, 01/06/1938.

CORREIO DA NOROESTE, anno VIII, nº 2154, 19/07/1938, p.1.

ESTRADA DE FERRO NOROESTE DO BRASIL. Relatório referente ao exercício de 1921. Bauru, p.3.

ESTRADA DE FERRO NOROESTE DO BRASIL Relatório da Diretoria referente ao exercício de 1933. Bauru, p. 15.

ESTRADA DE FERRO NOROESTE DO BRASIL Relatório da Diretoria referente ao exercício de 1935. Bauru, p. 12.

FOLHA DO POVO, anno 5, nº 501, 24/04/1939, p.2 (grifos meus).

GHIRARDELLO, N. “A arquitetura e o urbanismo na Revolução de 1930”. In: Seminário O pensamento da direita no Brasil: perspectivas e ideologia, mídia e cultura. Unesp- Marília, Faculdade de Filosofia e Ciências. 13 de agosto de 2002 (b).

Nos trilhos do passado, o conjunto da NOB em Bauru. In: $5^{\circ}$ Seminário

Nacional e $1^{\circ}$ Encontro Latino Americano de Preservação e Revitalização Ferroviária. Unimep. 15 a 18 de Agosto de 2001.

GUEDES, E. A. Parecer no processo de tombamento das estações ferroviárias de Tibiriçá, Val de Palmas e Curuçá. Processo no 30300/03. Bauru: 2003.

NEVES, C. História da Estrada de Ferro Noroeste do Brasil. Bauru, São Paulo: Tilibra, 1958.

POSSAS L. M. V. Mulheres, trens e trilhos: modernidade no sertão paulista. Bauru: EDUSC, 2001.

O BAURU, anno XV, no 723, 28/07/1921, p.1.

O BAURU, anno XVI, no $852,09 / 11 / 1922$, p.2.

REIS FILHO, N.G. Quadro da arquitetura no Brasil. São Paulo, Perspectiva, 2002. 
REVEL, J. "A invenção da sociedade”. In: Coleção Memória e Sociedade. Lisboa, Portugal. Difel. 1989. 